\title{
Mind-Body Wellness Project: An Exemplar Case
}

\author{
Masoud Ghaffari* \\ Department of Nursing and Health, Benedictine University, USA
}

*Corresponding author: Masoud Ghaffari, Benedictine University, Department of Nursing and Health, USA.

Received Date: February 11, 2018

Published Date: March 06, 2019

\begin{abstract}
A growing body of literature concerning the inherent stresses of nursing and medical education report especially high stress levels, in some cases higher than those students in other health professions. Nursing students have attributed their stress to academic, financial, work-related, and interpersonal circumstances. Studies have shown that there is a correlation between the stressors that college student's experience, and an increase in levels of stress, anxiety and depressive symptoms. High stress and anxiety impede concentration, memory, and problem-solving ability, which, in turn, adversely affect academic performance and learning. Purposes of this qualitative participatory action research were to design, implement, and assess the extracurricular wellness project for the first-year undergraduate nursing students. We evaluated: the effectiveness of a holistic wellness program in enhancing first-year nursing students' overall health (physical, psychological/social, and spiritual), and 2) the effectiveness of the program in enhancing first-year nursing students' learning and their performance in pathophysiology course. A purposive sample of $156(\mathrm{~N}=156)$ first-year junior nursing students participated in this study. Thematic analysis of data related to effects of holistic wellness program on the students yielded two main themes: 1) observed-felt effects and 2) unobserved-felt effects. This article briefly describes the study; however, the main focus will be on describing practicing "mindfulness" as an exemplar case to maintain and enhance mind-body wellness.
\end{abstract}

Keywords: Nursing education; Nursing curriculum; Mind-body wellness; Mindfulness

\section{Introduction}

Economic, political, and social pressures are the impetus for change in the health care delivery and educational systems. Shifting demographics and disease patterns, escalating health care costs, expanding healthcare technology, and diminishing access to health care have contributed to the changing health care delivery system. All these factors have implications for nursing education. As health care continues to change, the education of nurses must also evolve to meet these changes. In 2010, two significant reports surfaced calling for radical changes in nursing education. The Carnegie Foundation's report Educating Nurses: A Call for Radical Transformation Benner P, et al. [1] and the Institute of Medicine's Future of Nursing report (IOM) [2] cited the inadequate preparation of nurses for practice in today's complex acute care environments [3]. Recommendations in these reports challenge nurse educators to move away from traditional methods of teaching by embracing evidence-based curricula that are both flexible and responsive to students' needs. Nursing education has gone through major changes. Laura A, et al. [4] reviews some of the changes in the profession from the old to the new era and describes some of the missing elements in nursing education in the 21st century. She explains that the nursing courses of the end of the 19th century were designed to prepare student nurses to: apply dressing, use "cups" and leeches; make beds, change, and move patients; prepare and cook for the sick; supply fresh air, warm and ventilate sickrooms; keep all utensils clean and disinfected; and make accurate observations and report to the physician. In 1988, the National League for Nurses (NLN) attempted to reform nursing education entitled "Curriculum Revolution: Mandate for Change." It did not succeed. In 2003, the NLN once again advocated a transformation of nursing education, via the creation of innovative pedagogies that will be effective in helping students learn to practice in rapidlychanging environments. In 2009, an initiative known as the Future of Nursing (FON), a joint project of the Institute of Medicine and the Robert Wood Johnson Foundation, began its critical review of the nursing profession which considered needed innovation in what to teach, how to teach, and where to teach [4]. 
The emphasis in nursing education has been on preparing students for their nursing boards (National Council Licensure Examination or NCLEX). The licensure exam tests only for minimum safe competency, but not the optimal competency. In a descriptive survey design, Candela, et al. [5] asked 352 recent nursing school graduates how well their educational programs had prepared them for their first jobs as registered nurses, and what, if any, did they identify as the inadequacies in their education? These recent graduates said they were inadequately prepared in pharmacology, clinical practice, leadership, and the use of patient electronic medical records. Most believed that their programs prepared them more for success on the NCLEX-RN exam than for practice [5].

Nurses are expected to be caring, empathic, responsible, and detail oriented. They must be able to direct or supervise others, correctly assess patients' conditions, and determine when consultation is required. They need emotional stability to cope with human suffering, emergencies, and other stresses. Heavy lifting is often required. Many of these are not addressed fully or adequately by the "standard nursing curriculum." Nurse educators do design their curricula according to the guidelines recommended/dictated by the accreditation agencies in which caring for and serving "others" is the focus. Ghaffari M [6] presented results of his research at National League for Nurses (NLN) Education Summit, 2007 "Evolution or Revolution: Recreating Nursing Education." The study was designed to explore and provide remedies for some of the deficiencies, within the context of his study entitled "Transforming Caring for Student Nurses into Nursing Care." He asserted that "caring for self" (i.e., student nurses and nurses) is prerequisite for optimal "caring for others."

America's colleges and universities began based on the notion that the classical liberal arts were essential to prepare moral, civic, and intellectual public leaders who followed professional careers. Interest in using college for explicitly vocational purposes began to be evident in the early and mid-nineteenth century, with the founding of West Point (1802), Rensellaer Polytechnic (1824), and some agricultural colleges in the 1850s [7].

We are currently witnessing a wholesale transformation of our universities, one in which institutions of higher learning are rapidly becoming professional and technical schools. "Higher education" is increasingly understood as an enterprise which seeks to provide students with those instrumental and technical skills directly tied to jobs. We are everywhere obsessed with credentials, certificates and qualifications at the expense of education. "Education" is now used synonymously with job or career preparation. The result of all this is that the university now presents itself like a business in the marketplace. This means keeping current "clients" (i.e., students) satisfied, while finding ways to capture a bigger market share [8].

The college years are crucial for educational and personal growth of many students. Many students look forward attending college and continuing their education. However, the transition from high school to college has been associated with a variety of stressors such as academic success, financial concerns, time management and the development of new peer relationships (Kumaraswamy, 2013). Studies have shown that there is a correlation between the stressors that college students experience, and an increase in levels of stress, anxiety and depressive symptoms [9]. Feld LD, et al. [10] suggest that anxiety and depression are some of the mental health issues college students encounter during their educational career. Anxiety affects 18\% of American adults with Generalized Anxiety Disorder (GAD) being the most common disorder among the college student population [11]. According to Song Y, et al. [12], $67 \%$ of college students with anxiety also experience depression. A study by Pedersen DE [13] demonstrated that the first episode of depression usually occurs during the college years. University students encounter academic and social demands that make them vulnerable to mental health difficulties [14]. Due to the increasing academic, social, and financial demands, the overall stress level of college students has increased from past decades [15]. In turn, these may have implications on academic success, productivity, substance use, and social interactions [16]. Although rates of anxiety, depression and stress are increasing among college students, there are limited interventions to help students cope with those concerns. Additionally, during high levels of stress, college students may use stimulant drugs, or so called "academic steroids." Finding ways to help students cope with stress, anxiety, and depression is imperative.

Therefore, a need for developing holistic and intelligent curricula is evident. This writing proposes and describes underlying principles of an "intelligent wellness curriculum." The three topics of Holistic Education, Intelligence, and Wellness will be discussed below.

Holistic Education--The holistic ideal can be traced back to indigenous cultures. In general, the aboriginal or indigenous person sees the earth and the universe as infused with meaning and Holistic educators try to recover this sense of meaning and purpose in education [17]. The term holism and holistic was coined by Jan Smuts from the Greek words "holus" which mean whole, and "holon" which means entity. Smuts saw holism as a process of creative evolution in which the tendency of nature is to form wholes that are greater than the sum of their parts [18]. The Greeks argued for a holistic approach in learning. Socrates can be seen as a holistic educator because he encouraged each person to examine his or her own life: "know thyself" $[19,20]$. The main element of holistic education is its focus on the interconnectedness of experience and reality. Holistic education attempts to develop a pedagogy that is interconnected and dynamic and thus is in harmony with the cosmos. In contrast, much of traditional education tends to be static and fragmented, ultimately promoting alienation and suffering [21].

Holistic educators believe that the body, mind and soul are integral aspects of human nature that should be considered in treating the whole person and that "holistic education is a more defensible, practical and effective approach to developing wellbalanced and healthy people who can be valued contributors to society according to their potentialities and the opportunities available to them. Holistic education views all aspects of life as interconnected, interrelated, and interdependent" [22]. Education should consider the whole person-- physically, mentally and spiritually-and recognize that we affect our environment and our environment affects us. 
Human Intelligence--Contemporary Western culture teaches tests, reinforces and rewards primarily two kinds of intelligence: verbal/linguistic and logical/mathematical. Current research has challenged all our previous notions about the nature of human intelligence. The work of Howard Gardner and others has identified multiple intelligences - distinct ways that we learn and know about reality - common to all human beings (Lazear, 1990). Although the theory was expanded later to be more wholistic, more so, is Trinity Paradigm of intelligence (TPI) emerged from a qualitative phenomenological study by Ghaffari M [24] which guides us to understand human intelligence holistically. Trinity Paradigm of intelligence includes three main realms:

- Intrapersonal: is within the realm of a person. Such a personal boundary encases and connects those elements that interact at the cellular, tissue, organ, and finally whole-body function.

- Interpersonal: represents interdependence and interconnectivity between the individual and others/ environment. Examples are being a good friend, a good parent, articulate, artistic, able to relate to environment, able to adapt, altruistic, caring, able to make commitments, and loyal.

- Transpersonal: represents interconnection of one to oneself and then to friends, family, community, society, environment, and ecosystem through a realization of a sense of wholeness, which enables one the freedom to get closer and ultimately unite with his or her spiritual essence. The attributes in this category univocally express self- realization, such as knowledge of the art of living a human life, self- actualization, liberation of mind, and spirituality [23].

The main theme that emerged from the study is "interdependence," the essence of the Trinity Paradigm of Intelligence (TPI). Accordingly, any actions, behaviors, intentions, and feelings that help initiating, maintaining, and evolving the interdependence within each realm and amongst the three realms are considered "intelligent."

The term wellness is new, but the basic concept is not. The term "arete" in ancient Greek referred to the noblest state of human functioning which includes a merging of body, mind, and spirit [25]. Jung and particularly Maslow who argued that striving toward selfactualization, growth, and excellence is a universal human tendency and overarching life purpose, developed this integration further $[26,27]$. Wellness was first coined in 1961 by Dunn, who is widely credited as being the "architect" of the modern wellness movement. He defined wellness as "an integrated method of functioning which is oriented toward maximizing the potential of which the individual is capable" [28]. Exercise has been defined as regular, patterned, leisure time activity pursued to achieve desirable outcomes, such as improved level of general health [24]. Mental functioning and mood can be improved by regular, proper exercise. Regular exercise is defined as a minimum of 20-30 minutes, 2-3 times per week. Regular physical activity is viewed as essential in the prevention of disease and improvement of general health [29,30]. Recently there has been considerable research into the measurement of college students' wellness because it is well documented that college students typically experience developmental and behaviorassociated threats to health that are unique to this phase in their lives [31]. There is a considerable amount of study in the literature that proposes wellness programs for college students [25,32].

\section{Literature Review}

As it was mentioned earlier, the focus of this article is on "Mind-Body Wellness" in general and particularly on "Mindfullness Practice". Therefore, the following will provide a literature summary related to the topic.

Physical activity is beneficial to both physical and mental health [33]. According to the World Health Organization (WHO, 2014), physical activity is defined as bodily movement that requires energy such as walking, swimming, and doing household chores. The WHO [34] recommends that adults between ages 18 and 64 should perform a 30-minute moderate-to-intense exercise five times per week. The range of health benefits includes a reduced risk of cardiovascular disease, increased muscle strength, and higher resilience [33].

In more recent years, yoga has become increasingly popular in the realm of physical fitness. It is gaining attention for the positive changes it can make on one's mental fitness. The benefits that yoga provides have been studied among populations that exhibit high levels of anxiety and stress, for example veterans and pregnant women. However, there is limited research on how yoga may benefit college students who experience a combination of anxiety and stress symptoms. Even though anxiety is common among the general and college population, according to epidemiological studies (APA [DSMV], 2013) approximately two-thirds of people affected by an anxiety disorder, are female. Researchers, who studied anxiety among college students, have found that certain characteristics such as academic performance can increase the risk of experiencing anxiety while in school. Upperclassmen, transfer students, students who live off campus, and students who report finances as a major stressor have the highest prevalence of anxiety and depression [9]. More than $80 \%$ of college students report feeling overwhelmed by everything that they need to accomplish, in both academic and personal lives; and $45 \%$ of students have also felt-"hopeless" at some point in their academic careers (American College Health Association) [35]. According to Milligan [36] many college students cite depression and anxiety as their biggest obstacle when it comes to achieving a higher level of academic performance. In a study by Eisenberg D, et al. [38], undergraduate students reported that their mental health issues affected their ability to perform well academically. Additionally, about $18 \%$ of these students reported missing assignment deadlines due to anxiety and/or depression. Besides alcohol and drug use, emotional overeating and lack of exercise are coping behaviors that can occur when people experience mental or emotional strain.

College students report that most of the stress they experience in college comes from the belief that they do not have enough time to complete their assignments nor do they have the knowledge they need to pass their courses [38]. 
There is an abundance of research that supports the positive effects of physical fitness on mental health. For many people daily physical exercise or activity is an essential component of self-care. The National Heart, Lung and Blood Institute (NHLBI) [39] reports that there are four types of physical activity: aerobic activity, muscle strengthening, bone strengthening, and stretching. Aerobic activity involves movements of large muscles such as legs and arms, which increase heart rate and respiration. The CDC [33] defined exercise as a form of aerobic activity or cardio that increases breathing and heart rate. Additionally, it is recommended that individuals practice a moderate type of exercise like walking or running for at least 10 minutes every day. The NIMH suggested that mild exercise might have a positive effect on mental and physical health [36].

Hegberg NJ, et al. [41] reported that over $50 \%$ of adults in the U.S. fail to engage in recommended levels of physical activity. Anderson E, et al. [42] suggested that exercise improves one's selfesteem and sense of well-being. Research has shown that shortterm exercise can reduce anxiety sensitivity by increasing tolerance for physiological symptoms such as rapid heart rate. Kangasniemi A, et al. [43] stated that individuals who exercise two or three times a week experience less anger, distrust and stress compared to people who did not exercise. Chapman, Fraser, Brown, and Burton (2015) reported similar results on physical activity reducing anxiety, depression, and the risk of chronic disease. Nevertheless, for many Americans keeping up a physical activity routine can be a cumbersome and difficult task. Since yoga has entered mainstream American culture it has been marketed as a simple alternative to more demanding physical exercise that improves both physical and mental health.

Yoga is an ancient therapeutic practice found in the Yoga sutras written in 3000 BC by Patanjali, a Sanskrit scholar [43]. Yoga originated in India over 4000 years ago Da Silva TL, et al. [45], and is defined as - "yoke", or -"union" that connects the body, mind, and spirit [45]. There is a wide range of yoga practices such as Viniyoga, Ashtanga, traditional Hatha, Kundalini, and Bikram. Viniyoga is restorative and meant to be a gentle and healing practice [46]. Kundalini yoga includes invigorating poses that will increase energy through breathing techniques and stretching movements [47]. Bikram yoga is performed in a high temperature room, which increases flexibility. Ashtanga yoga includes a series of strenuous poses, and fluid movements. Traditional Hatha is a modern version of yoga that encompasses easy and basic movements [47]. Researchers have found significant support for the benefits of Hatha yoga on improving distress intolerance Medina J, et al. [49] and executive functioning Gothe NP, et al. [50], and significantly lowering stress levels by improving mindfulness [50]. Practitioners move slowly into positions, or asanas. While holding these asanas, awareness is brought to the breath and how the body responds to each position [50]. In Hatha yoga, being mindful and present are techniques that are used to relax the body, allowing individuals to ease the pain that has built up from stress and anxiety. There are several yoga practices, but the basic tenets of yoga focus on combining stretching, deep breathing, and mindfulness meditation [43]. By stretching and toning the muscles, the spine and joints become more flexible. Following the practice of yoga, relaxation of the mind and body allow for individuals to face situations and perform tasks with ease [51].

Meditation, which includes mindful breathing and sitting, is intended to relax and focus the mind. Many adults practice yoga and tai chi to improve their concentration as well as to help with weight loss and healthful living. research has shown that a meditation and yoga relaxation program over an 8-week period can significantly decrease students' levels of stress (La Forge, 1995). Academic achievement and good health are both part of the school curriculum and part of students' success. By developing positive attitudes about health and fitness, students can apply some of the strategies learned in mindful exercise to increase their concentration and memory [52]. For example, the practice of hatha yoga provides emotional regulation [53].

Mindful exercise is a process rather than a strictly goal-oriented activity and involves proprioceptive awareness. Mindfulness is defined as the ability to focus on the present moment with openness and acceptance [54]. Hewett ZL, et al. [56] examined the effects of an eight-week Bikram yoga program (practiced in high temperature rooms) on a healthy population of young females. The researchers noted that there was a significant reduction in perceived stress and an improvement in flexibility and balance. Another significant result was the negative correlation between mindfulness and perceived stress. Being mindful helps regulate reactions to stressful events that may be unavoidable. Several other studies have generalized that exercise and physical activities can be effective in improving quality of life and relieving anxiety [55]. Da Silva TL, et al. [45] found in their meta-analysis that yoga is an effective and possibly a better treatment than medications for mood and anxiety disorders. Cramer H, et al. [56] conducted a metaanalysis, which focused on pre-existing research covering several different types of yoga. A total of 44 different yoga styles were covered, including, Ashtanga, Kundalini, Bikram, and Hatha yoga. Most of the studies they analyzed reported positive results when comparing yoga groups to no-treatment control groups, however their meta-analysis revealed that the type of yoga practiced did not have a direct effect on improvement outcomes.

According to Kabat Zinn J [60], mindfulness is best defined as "the awarenessthat emerges through paying attention on purpose, in the present moment, and nonjudgmentally to the unfolding of experiences moment by moment".

That definition actually has three parts:

(a) the first part highlights mindfulness as an active process, involving active attention that leads to awareness

(b) the second part focuses on the present rather than dwelling on the past or the future; and

(c) the third part signals that attention is nonjudgmental and accepting, that is, the present moment being neither good nor bad.

Ultimately, it involves "attending to the external environment such as sights, sounds, and smells, as well as to internal bodily sensations, thoughts, and feelings" [58]. 
The following is a list of what occurs when students participate in mindfulness practice [59]:

a. Students become aware of their breath.

b. Students identify the various physical sensations of an emotion.

c. Students absorb thoughts as they pass through their minds.

d. Students develop awareness of and attention to all the sounds in the room.

e. Students sense what happens in their bodies when there is stress.

f. Students identify the thoughts that arise when they experience boredom.

g. Students learn to allow their stomachs to rise and fall with each breath.

Mindfulness meditation can help students understand that they are the producers of their thoughts, and their thoughts can influence feelings and actions.

The practice of Yoga - which means "union," goes beyond Asana; Yoga is a much broader system fostering ethical behavior and human development. The Yoga Sutras [60] influenced by details the eight "limbs" or steps prescribed in the Yoga Sutras including Yama (abstentions), Niyama (observance), Asana (discipline of the body), Pranayama (breath), Praryahara (withdrawal of the senses from external object), Dharana (concentration), Dhyana (steadfast meditation) and Samadhi (oneness with the object of meditation).

Yoga has been found to promote increased focus in children through the practice of controlled breathing which lowers the heart rate, calms the mind and regulates the autonomic nervous system [61]. This leads to "improve mental alertness, academic performance, readiness to learn, and enthusiasm for learning" [36,62]. Hopkins JT, et al. [66] found that yoga enhances concentration, also provides an opportunity for practitioners to experience the rewards of perseverance as they work to master new postures, acquiring a sense of accomplishment, self-satisfaction, self-discipline, and inner strength [64].

Yoga also provides strategies that enhance positive social interactions allowing students to "learn to relax, teach self-control, and instill a sense of peace in their daily lives" [65]. In addition, yoga practice reduces students' state of anxiety, general tension, and stress symptoms [66]. Although yoga is an individual activity, it is usually practiced with others, and lessons frequently emphasize peaceful interactions and the importance of the individual within the group [67]. Cohen Harper J [71] found that children practicing yoga had increased social awareness and improved relationship skills; she found that they form "a sense of community without the need for an opponent or enemy".

\section{Statement of the problem}

A major study Hensley LD [72] reported a decline in physical education in postsecondary schools over several decades from the early 1960s through 1998. Although the exact number of schools that made changes to physical education during this period was not reported, the Hensley's study [69] suggests that the trend to reduce or eliminate physical education broadly affects many post-secondary schools. Evidence-based research on the current health status of college students and society at-large suggests improvements and increases of physical activity are vital to students and society -not its reduction/elimination. The National Association of Sports and Physical Education (NASPE) [70] recommends that physical education constitute a significant part of a college/university's education mission because they believe the benefits of physical activity enhance all aspects of a student's health and development, including emotional, social, and intellectual.

\section{Purpose of the study}

Purposes of this qualitative participatory action research (PAR) were to design, implement, and assess the extracurricular wellness project for the first-year undergraduate nursing students. We evaluated:

1) the effectiveness of a holistic wellness program in enhancing first-year nursing students' overall health (physical, psychological/social, and spiritual),

2) the effectiveness of the program in enhancing firstyear nursing students' learning and their performance in pathophysiology course.

\section{Participants}

A purposive sample of $156(\mathrm{~N}=156)$ first-year junior nursing students participated in this study. There were 127 females and 29 males. Participants ranged in age from 21-47 years.

\section{Method, design, and procedure}

To design, implement, and evaluate effectiveness of a holistic wellness program for the first-year junior nursing students, participatory action research (PAR) was used.

Participatory Action Research (PAR) provided a holistic approach for assessment and built both relationships and collaboration among the school's stakeholders for sustainable change. The stakeholders were first-year junior nursing students, faculty, and staff at Center for Physical Activity (CPA), and spouses/ children. Over the course of one semester, the study moved through three distinct, yet overlapping and cyclical phases--assessment, implementation, evaluation. The participants had the opportunity to provide written feedback and include it in their weekly reflective paper.

The PAR approach is increasingly recognized as a highly effective method of enhancing relevance and value to health research. Our PAR approach combined research with education and co-learning to democratize the knowledge production, and so affect the relevance and quality of the knowledge and the likelihood that it would influence change. The core values include cooperation, with equal contributions from everyone present, and co-learning; promoting systems development; capacity building; and empowerment. 
The holistic wellness program was designed to be an "extracurricular" to allow voluntary participations of the interested students. The program was offered to the nursing students who registered for undergraduate pathophysiology course. Pathophysiology refers to the scientific study of disease or abnormal processes. Any ailment of the body that disturbs its normal physiological processes is the study of pathophysiology. The process involves looking for specific malfunctions that cause or come from disease. Nursing students take a pathophysiology course in college to prepare them to identify these abnormalities. Pathophysiology is study of alterations at cellular, tissue, and body organ levels. Many students have trouble learning the material due to depth and quantity of the content. These prevent them to be able to make connections with "real" life situations, therefore, must memorize the facts in order to pass the tests and complete the course.

At the first day of class, the course objectives and expectations were explained. After discussing the required curricular activities and course expectations, the topic of "extracurricular/extra credit" activities were introduced. Extra Credit can be an effective tool in classroom if used in the correct manner. It provides students with an incentive to go above and beyond the class material to: enhance lessons, deepen the learning for students, and can also help struggling students by providing them with additional learning opportunities while allowing them a means to improve their grade. The opportunity was offered to all the students. Their voluntary participation was emphasized. Wellness program was the only extra credit activity for this course. Students were given a week to think about the program and if they decide to participate, they needed to sign the consent form indicating that their participation was voluntary; could withdraw at any point during the semester; needed to consult with their family physician and receive medical clearance for participation, if needed. Through cooperation with the director and staff of the Center for Physical Activity of the university, it was agreed that the students only use that facility on campus for their project; sign-in sheets were prepared and was marked on only by the staff that showed when the students start their activity for the day and time, they complete their activities. In addition to having many types of equipment, the CPA has a swimming pool, racquet ball courts, indoor track, etc. Students were given an opportunity to participate in their favorite physical activities, at least 30-45-minute session, 3-4 times a week, for the entire semester (12 weeks).

They were able to gain 12 extra points or $10 \%$ of the course grade by completing the wellness program. No partial credit was given. In addition to exercise portion of the program, students were required to submit one-page reflective paper on a weekly basis. In that, they described their activities for the week, made suggestions for the program modifications, and they needed to connect at least one physiologic/pathologic alteration they experienced with the lecture material for the week. This would allow them to think creatively and connect the lecture material as they were presented in their textbook with a "real" life situation. For example, if they received an injury and the lecture topic was about inflammation for that week, they could have extracted information related to the inflammatory process from their textbook, apply them to their own condition, and present them in their weekly reflective paper. Weekly feedback was provided which allowed for immediate modifications in the wellness program, if were needed. Most of the changes made were related to logistical issues.

Participants were given an option to providing a summative program evaluation in narrative form or participate in a focus group interview. Therefore, data sources included 79 narratives $(n=79$, female $=70$, male $=9$ ) and 14 focus groups, about 5 in each group ( $n=77$, female $=71$, male=6). Each focus group interview took about 1-1 $1 / 2$ hours and conducted in a private conference room on campus. Interviews were digitally audio recorded.

A review of the literature helped the researcher to first become informed about the current state of the science, existing theories and constructs which eventually guided design of the study. The university IRB granted permission to "evaluate the program." After receiving detailed information about the research, the participants gave written informed consent prior to their participation. The participants were assured that interview data and their narrative feedback were to be kept confidential, and that participation in this study was voluntary and would not affect their status in school in any way. Anonymity was assured by code-numbering the interviews and the written documents. The interviews were digitally audiorecorded and transcribed verbatim. Field notes were taken during and after each interview.

Some guiding questions were posed to the participants to explore their perspectives and perceptions and to elicit data:

a. What were your initial thoughts, feelings, and perceptions when you heard about the exercise project?

b. How was your first day at CPA?

c. How was your interaction with the CPA staff; facility; equipment availability; etc?

d. What days of the week and time you exercised? and why?

e. What type of exercises you did the most/least? and why?

f. Did you work out by yourself, or in a group, with your classmates? Why?

g. What were the most/least 'fun' aspects of the activities? Why?

h. Have you noticed any observable changes as direct results of the project in your physical, emotional, spiritual conditions, as well as on your study habits?

i. Do you recommend offering the project to the upcoming classes? Why?

j. What do you recommend for improving the project?

\section{Data analysis and results}

Data analysis was performed manually. Critical themes emerged out of the data by inductive analysis [71]. Guided by Max Van Manen [75] suggested criteria for analyzing qualitative research data, I read and re-read the transcripts and the reflective papers 
to identify thematic statements. Thematic analysis of data related to effects of holistic wellness program on the students yielded two main themes: 1) observed-felt effects and 2) unobserved-felt effects.

An audit trail was developed that documented each participant's comments and tracked the specific data and the transcription page containing the quotations. An audit trail was maintained as a document to assure confirmability and dependability [73]. Member checks performed to assure accuracy of the transcribed data. Only 3 students responded to this inquiry. Expert checks were employed to confirm the accuracy/credibility of the findings. As part of the consent process, participants agreed to have their class journals be used as research data as long as their anonymity was maintained. Conscious efforts were made to establish confidence in the description of the meaning of the data and credibility of data by presenting my preliminary findings to my research colleagues in order to achieve collaborative analysis [74]. The use of multiple methods of data collection such as in-depth interviews, notes taken during and after the interviews, and students' reflective journals (methodological triangulation) assured credibility [75]. Dependability and confirmability were assured through an audit process. To assure transferability or applicability of the emerged results, thick descriptive data including demographic data, procedure, interview method and sample excerpts are provided to inform readers to make a transferability judgment.

The observed-felt effects are those which were vividly expressed by the students as the effects that they experienced, and the effects were obvious and observable to them. For example, one participant expressed energizing effects of the wellness.

Well with me I felt better after I exercised. A lot of times I could go there (CPA) and be tired and be mentally drained and after working out with my friends I would just feel better. Physically and mentally...I would feel like I had a lot more energy or something. I would feel better about myself after I left.

Alterations in body weight usually are perceived as effectiveness or lack of in a wellness program.

When you talked about the wellness program in class, and added that we even can receive extra points ...I said to myself, great ...I am going to work on it to get rid of my love handles that I have been carrying with me for the past couple of years and I don't even need an extra point ...I need extra push (laugh). I have lost 4 pounds already.

Some of the participants took advantage of the wellness program and tried to enhance their already in place routines.

I was so glad that you offered this extra credit program. Many of my classmates are not used to exercise and they are very out of shape. I thought you were offering the wellness program only to those who do not exercise. You said anyone can participate, and I said cool. I am exercising anyway, so, now, I can work on and improve my heart rate and endurance since you wanted us to do it for the entire semester anyway. This was my incentive.

The second emerged theme was related to unobserved-felt effects. These were the effects which were not quite evident to the participants. However, they were expressed by the participants during the interview or were evident in the narrative statements. Spiritual and to some extent, social effects of the holistic wellness program can be placed in this category. Positive social effects of the program were expressed by almost all the participants.

"Probably my favorite would be volleyball because a lot of the group that I studied with we would go and play volleyball and then we would go study. And it was so different than our study regimen, which was so stressful and intense, and then we got in there and we laugh."

"I am kind of shy and I did not want to participate in the project. When you offered an orientation session, I decided to go to CPA to see what is going on. I realized the first day that I was not the only one, but several of my classmates were hesitant to go there too. While you were showing us around, we talked to each other and made friends. Also, combined positive psychosocial effects were expressed."

"Well for me it was getting up there and just walking because with the nursing program you just don't have time between school and study ...so just even walk something as simple as that. Getting up there walking, being with my friends, talking about stuff, to me that frees my mind and the stress level and I was exercising very low impact."

"You know, I am glad you offered this ...you probably knew how we feel after the exam. Myself and some of my classmates we always go to CPA after the exam and use our time to walk on the track. We talk about test questions, answers and things like that [researcher: is that stressful?] actually not, we vent and learn from each other. It feels much better after that."

Spiritual effects are categorized as unobservable but felt attribute. Asking direct questions about the spirituality usually do not yield expressive responses due to dense religiosity of the people in this area. Many equate spirituality with religion.

"[Researcher: do you think participating in the wellness program had any positive or negative spiritual effects on you?] spirituality effects ... (long pause) ... I don't think so. I attend church regularly. My spiritual practices take place there ... I mean I exercise here and it is going to make me stronger, healthier and a better person. But, that is what I see in here."

"Sometimes, I do pray when I am at the CPA, but that is aside from what I do as a student. [Researcher: is there any difference between spirituality and religion?] oh ... I don't think so ... we all are religious, we all are spiritual, we all believe in the same father, no matter if you call it spirituality or religion."

However, many participants expressed positive spiritual effects of the holistic wellness program.

"[Researcher: would you tell me what type of exercises you do as part of the wellness program?] I like stationary biking and I spent most of my time on that. [Why?] you know, when I am on the bike, I put on my headset, play a soft music, meditate. This gives me sense of peace and calmness. [Any spiritual effects?] yes, when I am in deep meditation, I can think much clearer, feel at peace with myself and listen to a soft music while try to forget what is and the people around 
me. It gives me a sense of connectedness. and listen to a soft music while try to forget what is happening around me and try to reflect on my personal life. This was the spiritual effect on me."

"I feel my muscles are getting stronger. I had problem walking a long distance ...but now I park my car here (Social Science Building) and walk to CPA with no problem ...I was told by my family that I look calmer and more peaceful since I've started exercising. Thanks Dr. "G" ...I hope you offer this project to your other classes too."

Participants in this study expressed their satisfaction for receiving two types of rewards: 1) internal (physical, psychosocial, and spiritual benefits) and 2) external (receiving extra points for their participations and having another opportunity to review the course contents). Many participants stated that writing weekly reflective paper was time consuming, but it was very beneficial to them and it was a good motivator to use the book to locate for pertinent information.

\section{Mindfulness practice}

Context-As the design section described, students were given an option of participating any wellness activities provided at the university Center for Physical Activity. Yoga is one of the classes offered to the students. Interested individuals who visit the Yoga section on the university website would see a welcome message stating "Welcome to the new, improved, and dynamic yoga experience provided by the CPA. Our vision and mission is to provide a positive and safe environment conducive for the integration of body, mind, and spirit - ultimately for the promotion of personal health and well-being. Discover the abundant benefits of various yoga practices and principles. These include asana (physical postures) to help realign and balance our physical body; pranayama (breathing techniques) to soothe, de-stress, and rejuvenate; as well as the exploration of meditation to nourish the soul. Many classes and workshops offered to accommodate individual needs. Check our current schedule and embrace your potential! --Namaste! Honoring one's self and all beings."

There are different yoga classes were offered at the CPA including: AM Flow Yoga, Gentle Meditative Yoga, Yin Yoga, Freedom Friday Flow Yoga, Yoga 101, Vinyasa Flow Yoga, Weekend Warrior Yoga, and Yoga for Life. Some of the students decided to use their exercise time to participate in yoga classes. There were two classes that most of the students participated, AM Flow Yoga which was offered early morning and the other class which was offered during lunch time. Hatha was the main style of yoga taught in both classes. Most of the students participated in the early morning class before going to class or between classes, during lunch time.

Each session took about an hour in which the basics of yoga, postures, breathing, and philosophy were taught. This class focused on "exploring meditation and yoga. We will focus on calming the "monkey mind", breathing, and going inward. The asanas will be gentle but invigorating! We will work on ourselves and with others, offering a few classes incorporating partner yoga. It is a great class for those who want to explore meditation on a deeper level and for those who struggle to stop the racing thoughts their mind. It is intended to teach you how to relax and be in the present moment."
Reflections-I asked the students to share their experience of practicing yoga as part of this extracurricular activity. Responses were all positive. These are a few examples:

"I was told by my parents and some of my classmates that I am a "jittery" person. Yoga helped me to calm down, relax, ...also helped me with my concentration...First, I was kind of ...not wanting to participate...I thought everyone was so flexible and I was going to feel embarrassed in front of everyone...It did not take that long that I noticed, I was not the only one [researcher: you felt better then?)...actually yes...this (yoga) is not like other sports. People there including the instructor, are not judgmental...they are there to help you to learn the poses and breathing...I felt very comfortable there..."

"I was working with a partner and we helped each other to learn the movements...that was a great group activity....that is not what I imagined about yoga practice."

"It (yoga) gave me a sense of peace...the breathing exercises were so great. Until then, I was thinking I was breathing correctly... but then I found I was breathing so shallow and superficially... now, I can use most of my breathing muscles. It also helped me with my concentration and helps me focus more in class...the only problem is that I had to get up early to make it to AM Flow class."

"[researcher: has yoga practice impacted your academic learning and study habit?] greatly...yes...I can tell you that I pay more attention to what I read, my patho grade has increased by 12 points from the first exam...I am calmer and have more focus."

"You talked about self-care, self-reflection, etc in class. I honestly did not get it. In our yoga class, we actually talk about these and talk about our potentials and we practice them...now, I have a good understanding about respecting myself and others...I am not the world, we are (laugh)."

\section{Summary and Discussion}

The results of the study revealed that the holistic wellness program was beneficial to the students and helped them to be healthier physically, mentally, and spiritually. There were several barriers to physical exercise and student participation in this program:

- Lack of time-nursing curriculum is very "heavy" in terms of content. Most of the college students nowadays are considered as non-traditional students. They work full or at least part time; single parent; etc.

- $\quad$ Exercise self-efficacy-is the extent or strength of one's belief in one's own ability to complete tasks and reach goals.

- $\quad$ Distance-many students live in the rural areas and very far from the campus.

- $\quad$ Family responsibilities-single parent; both parents working full time; taking of children, etc.

- Type of sport-some students were interested in participating in certain sports for which the equipment was not provided, e.g., fencing, indoor soccer, etc. 
- $\quad$ Lack of self-discipline-a few students had to withdraw from the program after a few weeks because they could not submit their weekly assignments on time.

Participants listed several motivating factors for participating in this program. They were receiving "extra points," stress reduction, socializing, become physically fit, provision of time to "vent," provision of time for meditation and reflection, exercising in an exemplary large, equipped, and clean facility.

Education for "life" has transformed to education for "living" in recent years. Institutions of higher education, due to economic realities, have turned into vocational institutions. Instant gratification and individualistic mentality have afflicted societies from West to East. Due to the vocational nature of institutes of higher education, courses in humanities, language, art, physical education, and other fundamental courses which give students a broader perspective on the world have been reduced to the bare minimum or have been eliminated altogether. As life becomes more complicated by several factors, many university students who experience numerous psychological, physiological, and social difficulties, develop several unhealthy lifestyle choices like, smoking, alcohol, eating too much that are often used for coping or as an avoidance to struggle with life stresses. Today's college students are not adequately prepared for today's or tomorrow's challenges.

Due to nursing shortage and need of communities for more health care professionals, more and more programs have forced to focus on graduating more students and in a short period of time. This has caused many nursing programs to move away from "student- centered" curriculum and prepare them only for passing the minimum safe competency exam. While nursing is physically and psychologically taxing, there are not almost any nursing curricula that prepare students for the challenges of the profession. This causes tremendous staff turn around and for many to leave the profession after a short trial.

Students who participated in yoga practice reflected on the experiencing more sense of interdependence, being a community, sense of being calm and at home, felt in peace in that no one judging them, connected with self, and others, being energized, having a better focus and concentration, and eventually observed improved academic performance.

The findings support what Farhi D [78] stated, in that the practice of yoga is not about self-improvement or making oneself better; rather, it is a practice of looking at one's self and finding the barriers that prevent one from connecting to the world. Farhi D [78] asserted that yoga practice is fulfilling to the world because it "cleans the mirror" and allows individuals to see the world around them. The practice of yoga is not a goal, but more of a journey to develop the best lens. Hatha yoga has been assessed in quality-oflife measures and scored on a variety of quality-of-life inventories, such as Quality Metrics SF-8 and S-12 self-report instruments. Studies on the effects of mindful exercise have also analyzed blood pressure, pulmonary function, balance, control, anxiety, tension, and spirituality. Mindful exercise has emerged as an effective fitness and health modality [76].
Researchers have long studied the components of mindfulness and learning [77-79] According to Langer EJ [82], actual learning is limited when learners work mindlessly. Likewise, the experiential learning theory (ELT) Kolb AY, et al. and Kolb DA [80,81] stresses the importance of direct experiences to the learning process. Both theories emphasize that learning occurs best when learners understand their strengths and weaknesses and how to use experiences to enhance their learning skills. ELT involves the two distinct processes of knowledge acquisition and knowledge transformation [78].

Langer EJ [82] identified the following as characteristics of mindfulness:

a. the creation of new categories,

b. openness toward new information,

c. acceptance of more than one view, and

d. a focus on process before outcome.

According to James W [83], "Owing to the fact that all experience is a process, no point of view can be the last one. Everyone is insufficient and off its balance, and responsible to other points of view than itself". Many theories of intelligence assume that there is an absolute reality, and that intelligence is positively correlated with an awareness of this reality [80]. An alternative view, based on mindfulness, is that individuals may define their relation to their environment in multiple ways.

The "Intelligent Wellness Curriculum," started in 2005 and has lasted for about five years. About 92\%-95\% of students that registered for pathophysiology course participated in this extracurricular project. The impetus for starting the program was the student nurses need for self- development and self-care. From the start and throughout implementation of the curriculum, we have been supported by a few and challenged by many. We were lucky and had full support of the director of university Center for Physical Activity. While the university built and maintained the state-ofthe-art facility partly with students' tuition money, many students did not know about the facility or did not have time to use it. The intelligent wellness program helped more than 1200 students (about $90 \%$ of the students in first year junior Bachelorette Nursing Program) to use the facility in the 5-year period. The program did not cost the institution any additional money. Curriculum and program such as this require favorable administrative and faculty support. Lack of those, resulted in ending the program after 5 years. Administration considerations on "what helps the students will help the college" allowed flourishing the program. On the other hand, several of the instructors believed that the extracurricular activity "wasted student time, prevented them to learn what they were supposed to," and "disservice to the student."

The intelligent wellness curriculum as an adjunct to a science course pathophysiology, provided opportunities for practicing physical health and wellness, socializing, and time for contemplation and meditation. Inherent in the program were opportunities for practicing other important and related tasks: time management, system thinking, pre-planning, problem-solving, 
building character, learning to care for self and others. Due to the nature of research methodology, there were no control groups to compare performance of the students in pathophysiology course for those who participated and those who did not. However, review of narrative feedback (reflective journals) received from the participants throughout the semester showed positive effects of the project in enhancing their learning pathophysiology contents. The present study also provided ample evidence for the yoga and mindfulness association, adding to the existing evidence.

\section{Acknowledgement}

None.

\section{Conflict of Interest}

No conflict of interest.

\section{References}

1. Benner P, Sutphen M, Leonard V, Lisa Day, Lee S Shulman (2010) Educating nurses: A call for radical transformation. Jossey-Bass, San Francisco, CA, USA.

2. (2011) The future of nursing: Leading change, Advancing Health. Institute of Medicine National Academies Press, Washington DC, US.

3. Allen P (2013) Preparing nurses for tomorrow's healthcare system. American Nurse Today 8(5): 46-50.

4. Laura A, Stokowski (2011) Overhauling Nursing Education.

5. Candela L, Bowles C (2008) Recent RN graduate perceptions of educational preparation. Nurs Educ Perspect 29(5): 266-271.

6. Masoud Ghaffari (2007) Transforming Caring for Student Nurses into Nursing Care.

7. Grubb, W Norton, Lazerson, Marvin (2005) Vocationalism in Higher Education: The Triumph of the Education Gospel. Journal of Higher Education 76(1): 1 .

8. Patrick Keeney (2011) "Vocationalism and Higher Education."

9. Beiter R, Nash R, Mc Crady M, Rhoades D, Linscomb M, et al. (2015) The prevalence and correlates of depression, anxiety, and stress in a sample of college students. J Affect Disord 173: 90-96.

10. Feld LD, Shusterman A (2015) Into the pressure cooker: Student stress in college preparatory high schools. J Adolescenc 41: 31-42.

11. Eisenberg D, Hunt J, Speer N (2013) Mental health in American colleges and universities: Variation across student subgroups and across campuses. J Nerv Ment Dis 201(1): 60-67.

12. Song Y, Lindquist R (2015) Effects of mindfulness-based stress reduction on depression, anxiety, stress and mindfulness in Korean nursing students. Nurse Educ Today 35(1): 86-90.

13. Pedersen DE (2013) Gender differences in college binge drinking: Examining the role of depression and school stress. The Social Science Journal 50(4): 521-529.

14. Bayram N, Bilgel N (2008) The prevalence and socio-demographic correlations of depression, anxiety and stress among a group of university students. Soc Psychiatry Psychiatr Epidemiol 43(8): 667-672.

15. Moore DR, Burgard DA, Larson RG, Ferm M (2014) Psychostimulant use among college students during periods of high and low stress: An interdisciplinary approach utilizing both self-report and unobtrusive chemical sample data. Addict Behav 39(5): 987-993.

16. Eisenberg D, Goldstein E, Hunt JB (2009) Mental health and academic success in college. The B.E. Journal of Economic Analysis \& Policy $9(1): 40$.

17. Ron Miller (2004) Educational Alternative: A Map of the Territory. Paths of Learning 20: 25.
18. Karen D Lee (1988) Toward a Philosophical Frame Work for Holism in Education. 450.

19. S Forbes (2003) Holistic Education: An Analysis of its Ideas in Nature.

20. J Miller (2007) The Holistic Curriculum. $2^{\text {nd }}$ edn.

21. Ana C Neves (2009) A Holistic Approach to the Ontario Curriculum.

22. Clarken, Rodney H (2013) Holistic Education. 1-5.

23. Jane E Myers, Thomas J Sweeney, J Melvin Witmer (2000) The Wheel of Wellness Counseling for Wellness: A Holistic Model for Treatment Planning. Journal of Counseling and Development 78 (3): 264.

24. Masoud Ghaffari (2010) Trinity Paradigm of Intelligence: An Ontological and Epistemological Inquiry. VDM Verlag Publishing, Germany, 474.

25. James Archer, Barbara S Probert, Larry Gage (1987) College Students' Attitudes Toward Wellness.Journal of College Student Personnel 28(4): 311-317.

26. CG Jung, (1958) The Undiscovered Self, trans. RCF Hall Mentor (Ed), Books, NY, USA. 22.

27. A Maslow (1970) Motivation and Personality. $2^{\text {nd }}$ edn 149.

28. Jane E Myers, Kirk Williard (2003) Integrating Spirituality into Counselor Preparation: A Developmental Approach. Counseling and Values 47(2): 150.

29. Ardell DB, (1992) How well do you 'talk your walk? American Fitness 10(6): 47-50.

30. Jerold S, Greenberg, Geoge B Dinitimann (1997) Wellness: Creating a Life of Health and Fitness.

31. Troy B Adams, Janet R Bezner, Mary E Drabbs, Robert J Zambarano (2000) Conceptualization and Measurement of the Spiritual and Population. Journal of American College of Health 48(4): 165-173.

32. John Davies, Roxanne Davies, Sue Heacock (2003) A Wellness Program for Faculty. Educational Leadership 60(8): 68-70.

33. (2015) The benefits of physical activity. Centers for Disease Control and Prevention.

34. (2014) Physical activity. World Health Organization.

35. American College Health Association. (2015). American college health association national college health assessment II: Reference group executive summary. United States.

36. Misra R, Mc Kean M, WestS, Russo T (2000) Academic stress of college students: Comparison of student and faculty perceptions. College Student Journal 34(2): 236-245.

37. (2011) Types of physical activity. National Heart, Lung and Blood Institute.

38. Milligan CK (2006) Yoga for stress management program as a complementary alternative counseling resource in a university counseling center. Journal of College Counseling 9(2): 181-187.

39. Anderson E, Shivakumar G (2013) Effects of exercise and physical activity on anxiety. Front Psychiatry 4: 27.

40. Kangasniemi A, Lappalainen R, Kankaanpaa A, Tammelin T (2014) Mindfulness skills, psychological flexibility, and psychological symptoms among physically less active and active adults. Mental Health and Physical Activity 7(3): 121-127.

41. Field T (2011) Yoga clinical research review. Complement Ther Clin Pract 17(1): 1-8.

42. Salmon P, Lush E, Jablonski M, Sephton SE (2009) Yoga and mindfulness: Clinical aspects of an ancient mind/body practice. Cognitive and Behavioral Practice 16(1): 59-72.

43. Combs MA, Thorn BE (2015) Yoga attitudes in chronic low back pain: Roles of catastrophizing and fear of movement. Complement Ther Clin Pract 21(3): 160-165.

44. Women's Health. Fitness and nutrition. 
45. Kramer AF, Mc Auley E (2014) The effects of an 8-week Hatha yoga intervention on executive function in older adults. J Gerontol Biol Sci Med Sci 69(9): 1109-1116.

46. Brisbon N, Lowery GA (2011) Mindfulness and levels of stress: A comparison of beginner and advanced hatha yoga practitioners. J Relig Health 50(4): 931-941.

47. Khanna S, Greeson JM (2013) A narrative review of yoga and mindfulness as complementary therapies for addiction. Complement Ther Med 21(3): 244-252.

48. Slovacek SP, Tucker SA, Pantoja L (2003) A study of the yoga ed program at the accelerated school. Program Evaluation and Research Collaborative 6: 588-612.

49. Howely ET, Franks BD (2007) Health fitness instructor's handbook.

50. Lopez Navarro E, Canto CD, Belber M, Mayol A, Fernadezalonso O, et al. (2015) Mindfulness improves psychological quality of life in communitybased patients with severe mental health problems: A pilot randomized clinical trial. Schizophr Res 168(1-2): 530-536.

51. Cramer H, Lauche R, Langhorst J, Dobos G (2013) Yoga for depression: a systematic review and meta-analysis. Depress Anxiety 30(11): 10681083.

52. Hewett ZL, Ransdell LB, Gao Y, Petlichkoff LM (2011) An examination of the effectiveness of an 8-week bikram yoga program on mindfulness, perceived stress, and physical fitness. Journal of Exercise Science \& Fitness 9(2): 87-92.

53. Oliver M (2009) What is mindfulness? Poster session presented at the annual meeting of the Association for Mindfulness in Education, Philadelphia.s.

54. Kabat Zinn J (2003) Mindfulness-based interventions in context: Past, present, and future. Clinical Psychology: Science and Practice 10(2): 144-156.

55. Hooker K, Fodor I (2008) Teaching mindfulness to children. Gestalt Review 12(1): 75-91.

56. Krishnamacharya E (1976) The Yoga of Patanjali. Visakhapatnam: Mithila Pub. Stone M., \& Iyengar, B. K. S. (2009). Yoga for a world out of order: Teachings on ethics and social action. Boston: Shambhala Publisher Inc.

57. Toscano L, Clemente F (2008) Dogs, cats, and kids: Integrating yoga into elementary physical education. Strategies: A Journal for Physical and Sport Educators 21(4): 15-18.

58. Hopkins JT, Hopkins LJ (1979) A study of yoga and concentration. Academic Therapy 14(3): 341-345.

59. Nelson DJ (2009) Yoga in the classroom. Journal for Health, Physical Education, Recreation \& Dance, 64: 12-13.

60. Kalayil JA (1988) A controlled comparison of progressive relaxation and yoga meditation as methods to relieve stress in middle grade school children. Dissertations Abstracts International 49: 197.

61. (2007) National Association for Sport and Physical Education (NASPE) College/University physical activity instruction programs: A critical piece in the education of young adults. Reston, Va.

62. Michael Q Patton (2002) Qualitative Research and Evaluation Methods 3. Thousand Oaks, CA: Sage: 615.

63. Cohen Harper J (2010) Teaching yoga in urban elementary schools. International Journal of Yoga Therapy 20: 100-110.
64. Hensley LD (2000) Current status of basic instruction programs in physical education at American colleges and universities. The journal of physical education, recreation and dance 71(9): 30.

65. Judith T Carboni (1995) A Rogerian Process of Inquiry. Nurs Sci Q 8(1): 23-37.

66. Max Van Manen (1997) Researching Lived Experiences: Human Science for an Active Sensitive Pedagogy.

67. Yvonna S Lincoln, Egon A Guba, (1985) Naturalistic Inquiry.

68. Kolb AY, Kolb DA (2005) Learning styles and learning spaces: Enhancing experiential learning in higher education. Academy of Management Learning and Education, 42(3): 193-212.

69. Farhi D (2000) Yoga mind, body \& spirit: A return to wholeness.

70. Bryant CX, Green DJ (2006) Ace personal trainer manual: The ultimate resource for fitness professionals. New York: Human Kinetics.

71. Kolb DA (1984) Experiential learning. Englewood Cliffs, NJ: PrenticeHall.

72. La Forge R (1995) Exercise-associated mood alterations: A review of interactive neurobiologic mechanisms. Medicine, Exercise, Nutrition and Health 4 17-32.

73. Langer EJ (1997) The power of mindful learning. Perseus Publishing, Cambridge, UK.

74. James W (1878) The meaning of truth. Harvard University Press, Cambridge, UK.

75. Kumaraswamy N (2013) Academic stress, anxiety and depression among college students- a brief review. International Review of Social Sciences and Humanities 5(1): 135-143.

76. Hegberg NJ, Tone EB (2015) Physical activity and stress resilience: Considering those at-risk for developing mental health problems. Mental Health and Physical Activity 8: 1-7.

77. da Silva TL, Ravindran LN, Ravindran AV (2009) Yoga in the treatment of mood and anxiety disorders: A review. Asian J Psychiatr 2(1): 6-16.

78. Medina J, Hopkins L, Powers M, Baird SO, Smits J, et al. (2015) The effects of a Hatha yoga intervention on facets of distress tolerance. Cogn Behav Ther 44(4): 288-300.

79. Anderson, E., \& Shivakumar, G. (2013). Effects of exercise and physical activity on anxiety.

80. Steiner N, SidhuT, Pop P, Frenette E, Elizabeth C, et al. (2013) Yoga in an urban school for children with emotional and behavioral disorders: A feasibility study. Journal of Child and Family Studies 22(6): 815-826.

81. Tummers N (2005) Yoga for your students. Strategies: A Journal for Physical and Sport Educators, 19(2): 35-37.

82. Rybak C, Deuskar M (2010) Enriching group counseling through integrating yoga concepts and practices. Journal of Creativity in Mental Health 5: 3-14.

83. Eisenberg D, Golberstein E, Gollust SE (2007) Help-seeking and access to mental health care in a university student population. Med Care 45(7): 594-601.

84. David Lazear (1990) Seven Ways of Knowing: Teaching for Multiple Intelligences. Australia: Hawker, Brownlow Education: 122. 